\title{
PROPOSTA DE TRAÇO PARA BLOCOS DE CONCRETO DE PAVIMENTO INTERTRAVADO
}

\author{
Charles Miguel Schvaickardt ${ }^{1 *}$, João Rodrigo Guerreiro Mattos ${ }^{2}$ \\ ${ }^{1}$ Engenharia Civil, Universidade de Santa Cruz do Sul-UNISC, 96.837-500, Santa Cruz do Sul, RS, Brasil. \\ 2 Universidade do Vale do Taquari-UNIVATES, 95.914-014, Lajeado, RS, Brasil.
}

*E-mail: charles_schvaickardt@hotmail.com

\begin{abstract}
RESUMO
O presente artigo apresenta um estudo técnico de traço de concreto para aplicação em pavimentos com blocos intertravados de concreto, promovendo ensaios para determinação das características e propriedades dos agregados, tais como, análise da composição granulométrica, massa unitária de material no estado solto e teor de umidade total. O objetivo principal deste trabalho é avaliar dosagens de traços experimentais, variando a adição de água e diferentes quantidades e proporções de agregados miúdos e graúdos, procurando conhecer suas influências. Outro parâmetro a ser analisado é a influência do tipo de cimento no traço. Para verificação destas atribuições, submeteu-se os blocos a ensaios de inspeção visual, avaliação dimensional, absorção de água e resistência característica à compressão. Com este estudo é possível justificar a fundamental importância da realização do controle tecnológico da confecção das peças para conseguir um produto final de melhor qualidade. Também foi possível realizar um comparativo da eficiência no custo-benefício dos blocos confeccionados experimentalmente no estudo, com os blocos confeccionados atualmente na fábrica de uma prefeitura municipal. Analisando os resultados, pode-se perceber o melhor desempenho gerado pelos traços propostos, verificando a influência dos parâmetros de materiais, vibro-prensa e dosagem. Por fim, pode-se propor uma dosagem tecnicamente mais adequada a ser utilizada na fábrica municipal para produção de peças para pavimentação, que atenda às exigências normativas e seja apropriada para utilização em ruas do Município.
\end{abstract}

Palavras-chave: Pavimento. Blocos Intertravados. Traço de Concreto.

\section{Introdução}

A constante e crescente ampliação de ruas com pavimentação em municípios requer qualidade dos seus componentes. Visto os elevados investimentos públicos necessários para a manutenção das ruas, urge alcançar um melhor desempenho e, consequentemente, maior durabilidade desses pavimentos. Sabendo que o controle técnico dos materiais influencia na resistência à compressão dos blocos e na aparência estética deles, então, faz-se necessário um estudo das condições dos componentes empregados no pavimento, visando a garantir o uso de materiais de boa qualidade na dosagem.

Por ser um serviço muito executado, não é raro que as prefeituras municipais possuam fábricas para confecção própria das peças pré-moldadas de concreto. Entretanto, percebe-se que falta controle na produção, o que impacta na qualidade final dos produtos confeccionados. Dessa forma, o presente estudo tem como objetivo realizar a dosagem de um traço para peças prémoldadas de concreto para pavimentos intertravados que atenda as especificações da NBR 9781/13 [1].

\section{Produção de blocos de concreto para pavimento}

Para Souza [2], a fabricação de blocos pré-moldados de concreto está sujeita a variações na qualidade, que é influenciada pelos equipamentos, materiais e a dosagem. Hood [3] destaca que o sucesso na produção de peças de concreto tem relação com o conhecimento dos materiais a serem utilizados, das propriedades exigidas e do processo de fabricação.

Os equipamentos para a produção das peças possuem diferentes particularidades na aplicação de energia de compactação, influenciando na resistência à compressão final do bloco. Destaca-se a importância em adquirir equipamentos com ótimo desempenho, resultando na produção de peças de qualidade. Os benefícios da produção em escala com o uso das vibro-prensas apontam para o controle de homogeneidade das resistências mecânicas, textura e dimensões que podem ser exercidos durante a fabricação dos produtos. FIORITI [1]

A NBR 9781/13 [1] menciona o emprego de agregados de procedência natural, industrial ou reciclada, com o critério de atender as especificações da norma de agregados para concreto. Conforme Fioriti [4], a granulometria do agregado altera a qualidade final das peças, modificando sua textura e sua resistência à compressão. Cruz [5] destaca a importância da escolha da proporção de agregados finos e graúdos, a fim de obter a menor quantidade de vazios. A mistura ideal será com a menor presença de porosidade, proporcionando a menor adição 
de aglomerante na dosagem, obtendo melhores resistências à compressão.

\subsection{Dosagem do concreto}

Para Fioriti [4], a dosagem de concreto para fabricação de peças pré-moldadas produzidas por vibro-prensas requer um produto de consistência seca, de modo a obter uma coesão sem prejuízo do formato, mantendo-se íntegro. A coesão da mistura depende da adequada quantidade de finos, aliado a vibração e prensagem. Para obter peças mais compactas e mais resistentes, deve-se acrescentar o máximo de volume de água, porém, sem afetar o formato após desmoldado. Segundo Cruz [5], as peças devem apresentar uma resistência capaz de manter seu formato intacto na fabricação, no assentamento e com os efeitos do tráfego de veículos.

De acordo Rodrigues apud Fioriti [4], a dosagem do concreto pode ser obtida pelo método do menor volume de vazios, que consiste em determinar a massa de cada agregado, realizando a comparação com a massa de mistura do agregado e areia preenchidos em um recipiente de volume padronizado. Os materiais secos devem ser divididos em diferentes proporções de teste e misturados. Utiliza-se um recipiente cilíndrico de diâmetro de $15 \mathrm{~cm}$ e altura de $17 \mathrm{~cm}$, com capacidade de 3 litros, depositando-se uma das misturas em 3 camadas. Compacta-se cada camada com 25 golpes de uma haste de $16 \mathrm{~mm}$ de diâmetro e comprimento de $60 \mathrm{~cm}$. A compactação da camada superior nunca deve atingir a camada inferior já compactada. Deve-se prosseguir com o nivelamento da superfície, retirando o material excedente e realizando a pesagem em uma balança. Com os resultados alcançados, é possível a determinação da proporção ideal de pedrisco e areia por meio da maior massa unitária em relação à proporção da mistura.

\subsection{Aceitação dos blocos de concreto}

A NBR 9781/13 [1], que rege as especificações e métodos de ensaio para peças de concreto para pavimentação, estabelece alguns requisitos para aceitação dos blocos. Para aprovação de um lote, não devem ser constatadas mais de 5\% de peças defeituosas, competindo ao consumidor optar pela troca das peças defeituosas, desde que as mesmas atendam os requisitos das dimensões, tolerâncias, resistência característica estimada à compressão e absorção de água.

Para Cruz [5], a variação das dimensões das peças prejudica o correto funcionamento do pavimento, ocasionando o desencontro das juntas. A diferença no tamanho compromete o modelo de assentamento desejado e, consequentemente, afeta a produtividade de execução do pavimento. A Tabela 1 destaca as tolerâncias nas dimensões, os limites de absorção de água e a resistência característica a compressão e abrasão mínima das peças de concreto.

Tabela 1. Tolerâncias dimensionais, absorção de água e resistência característica a compressão e abrasão das peças de concreto. (Adaptado pelo Autor da NBR 9781/13 $\underline{[1]) .}$

\begin{tabular}{|c|c|c|}
\hline \multicolumn{2}{|l|}{ Dimensões } & Tolerâncias \\
\hline Comprimento & $\geq 97 \mathrm{~mm}$ & $\pm 3 \mathrm{~mm}$ \\
\hline Largura & $\leq 250 \mathrm{~mm}$ & $\pm 3 \mathrm{~mm}$ \\
\hline Espessura & $\geq 60 \mathrm{~mm}^{1}$ & $\pm 3 \mathrm{~mm}$ \\
\hline \multirow{2}{*}{ Absorção de água } & Média & Individual \\
\hline & $\leq 6 \%$ & $\leq 7 \%$ \\
\hline Solicitação & $\begin{array}{c}\text { Resistência característica } \\
\text { à compressão }\left(\mathbf{f}_{\mathrm{pk}}\right) \text { aos } 28 \\
\operatorname{dias}^{2}\end{array}$ & $\begin{array}{l}\text { Resistência à abrasão } \\
\text { Cavidade máxima }\end{array}$ \\
\hline Tráfego de pedestres, veículos leves e veículos comerciais de linha. & $\geq 35 \mathrm{MPa}$ & $\leq 23 \mathrm{~mm}$ \\
\hline $\begin{array}{l}\text { Tráfego de veículos especiais e solicitações capazes de produzir efeitos de } \\
\text { abrasão acentuados. }\end{array}$ & $\geq 50 \mathrm{MPa}$ & $\leq 20 \mathrm{~mm}$ \\
\hline
\end{tabular}

1 Deve apresentar múltiplos de $20 \mathrm{~mm}$;

${ }^{2}$ Lote inferior a 28 dias deve apresentar resistência característica à compressão mínima de 80\%;

${ }^{3}$ Ensaio facultativo.

\section{Estudo experimental de traço de concreto para peças}

$\mathrm{O}$ estudo elaborado foi executado numa fábrica de produção de peças pré-moldadas de concreto para pavimentação, situada juntamente à Secretaria de Obras de um município no Rio Grande do Sul, sendo destinada à pavimentação de ruas vinculadas ao programa de Adesão à Parceria entre a Prefeitura Municipal e proprietários de imóveis.
Este sistema é regido por Lei e consiste em um plano básico de pavimentação para beneficiar moradores do município. Os materiais para fabricação dos blocos, meio-fio e tubulações são custeados pelos moradores e a mão de obra para fabricação e execução é concedida pelo órgão público. 


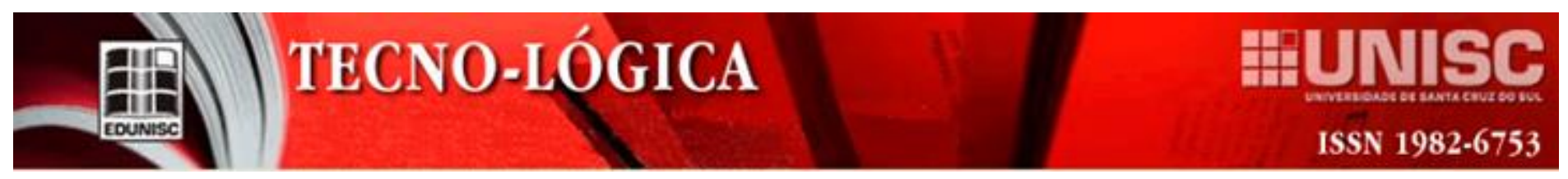

A fábrica de blocos teve sua implantação na década de 1980. Em 1993, foi adquirida a vibro-prensa utilizada até hoje. Trata-se de um equipamento para moldagem dos blocos, da empresa Vibramaq, modelo PPB 60 AVP 4B. O equipamento é uma prensa pneumática, semiautomática, acionada manualmente por 3 válvulas tipo "pedal". A fabricação das peças é realizada com espessuras de $8 \mathrm{~cm}$ em virtude do emprego em ruas de pequena circulação de veículos, ou seja, baixo e médio tráfego. A Figura 1 demostra os blocos em período de cura do concreto, produzidos na Secretaria Municipal.

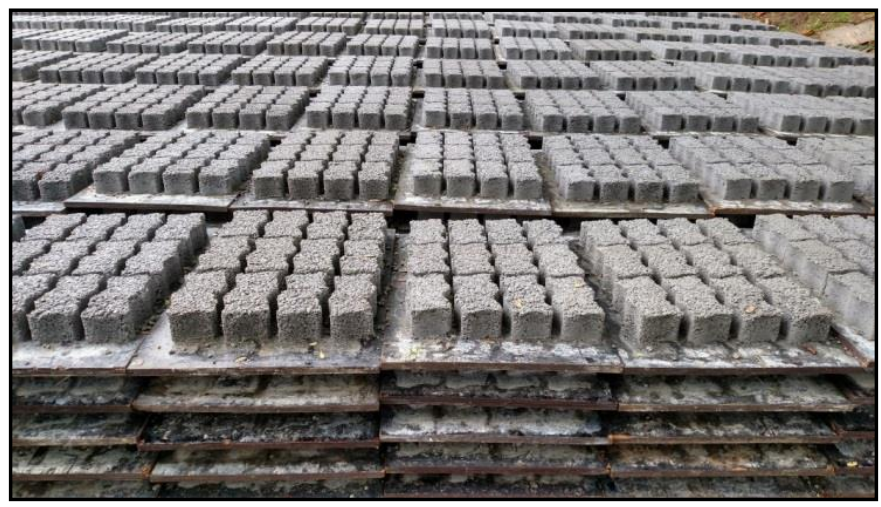

Figura 1 - Blocos de concreto intertravado produzidos na fábrica.

A produção de blocos de concreto é dosada em volume, traço definido no período de implantação da fábrica. O traço é composto por cimento Portland CP IV - 32 [6], agregado miúdo e graúdo [7], ou seja, areia grossa e brita 0. A água é adicionada sem qualquer controle na produção dos blocos, sendo verificada visualmente pelo operador da misturadora. A Tabela 2 apresenta o traço utilizado, identificado como "P", com referência à Prefeitura Municipal.

Tabela 2. Traço em volume utilizado na fabricação dos blocos de concreto.

\begin{tabular}{|c|c|c|c|c|c|c|}
\hline Identif. & Unid. & Cimento & Areia & Pedrisco & $\begin{array}{c}\text { Total } \\
\text { Agregado }\end{array}$ & Água \\
\hline $\begin{array}{l}\text { Traço em } \\
\text { volume }\end{array}$ & $\mathrm{m}^{3}$ & 1 & 3,50 & 2,50 & 6,00 & \multirow{5}{*}{ Visua } \\
\hline $\begin{array}{l}\text { Massa } \\
\text { unitária }\end{array}$ & $\mathrm{kg} / \mathrm{m}^{3}$ & 1388,89 & 1738,44 & 1495,11 & - & \\
\hline $\begin{array}{l}\text { Teor de } \\
\text { umidade } \\
\text { total }\end{array}$ & $\%$ & - & 3,13 & 1,65 & - & \\
\hline $\begin{array}{l}\text { Massa } \\
\text { unitária } \\
\text { natural }\end{array}$ & $\mathrm{kg} / \mathrm{m}^{3}$ & - & 1792,86 & 1519,78 & - & \\
\hline $\begin{array}{l}\text { Traço em } \\
\text { massa }\end{array}$ & $\mathrm{Kg}$ & 1 & 4,52 & 2,74 & 7,25 & \\
\hline
\end{tabular}

Considerando os componentes e equipamentos utilizados na dosagem e fabricação dos blocos, a realização deste estudo utilizará os mesmos materiais e procedimentos. Serão realizados ensaios para conhecer as características e propriedades dos materiais utilizados no concreto. As peças confeccionadas no estudo serão analisadas em suas condições geométricas, resistência à compressão, absorção de água e aspecto visual dos blocos de concreto, conforme critérios da NBR 9781/13 [1]. Objetiva-se promover um melhor desempenho para as peças pré-moldadas de concreto, visando uma melhor relação custo-benefício atendendo os critérios estabelecidos pelas Normas Regulamentadoras. O fluxograma do estudo é apresentado na Figura 2.

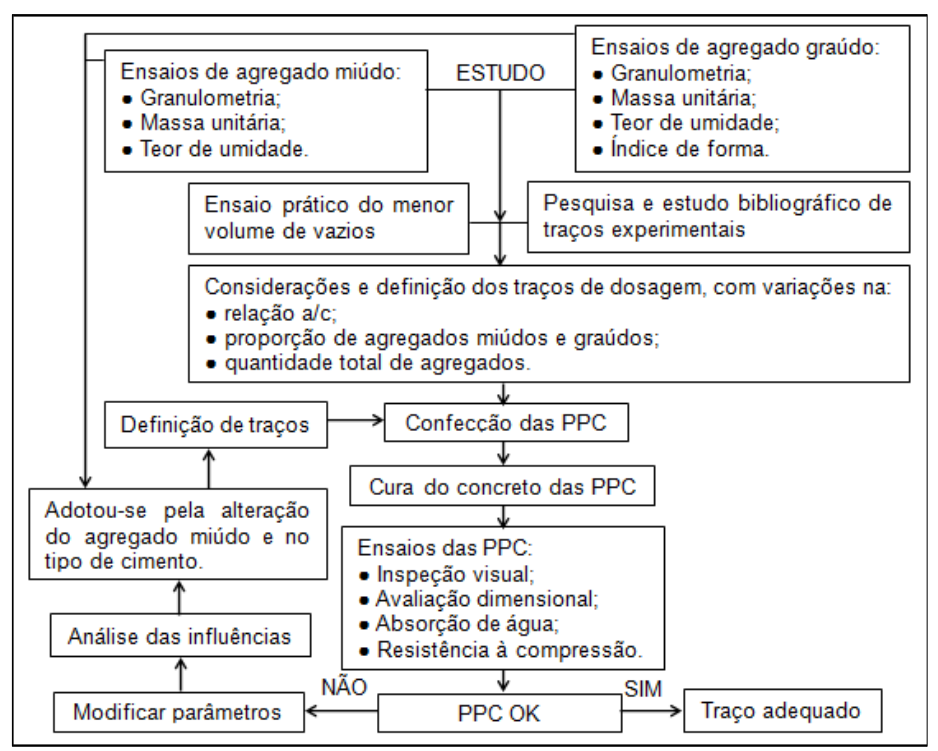

Figura 2 - Fluxograma do estudo.

\subsection{Materiais utilizados na dosagem do traço}

Considerando a fabricação das peças pré-moldadas de concreto, foram utilizados os cimentos Portland Pozolânico CP IV - 32 [6] e CP V - ARI [8], do Grupo Votorantim, para a fabricação dos blocos para ensaios. O agregado miúdo utilizado na fabricação dos blocos tem procedência da extração do Rio Jacuí, no município de Rio Pardo/RS. Os agregados graúdos proveem do processo de beneficiamento do material extraído do Vale do Rio Pardo/RS. A Figura 3 ilustra os agregados empregados no concreto. [9-10]

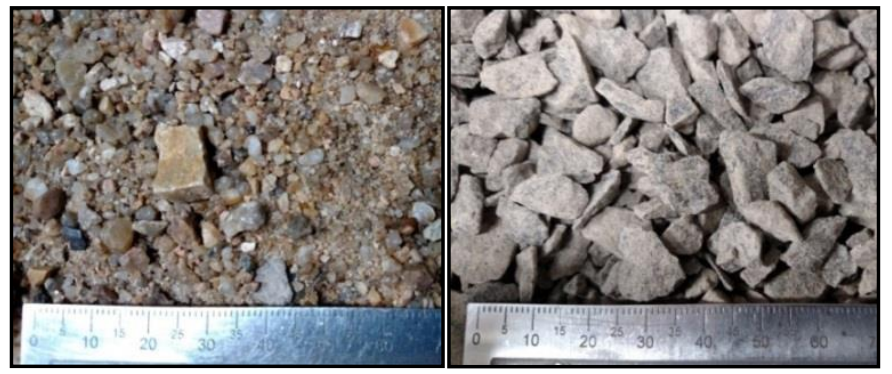

Figura 3 - Aspecto visual dos agregados miúdos e graúdos. 
Analisando a Figura 3, verifica-se que os agregados graúdos são caracterizados por apresentarem grãos na forma lamelar. A lamelaridade do agregado é prejudicial ao concreto, visto que a resistência é afetada devido à fragilidade dos grãos, que favorece a formação de bolhas, originando a presença de vazios, e ainda, a necessidade de maior quantidade de cimento para compensar a resistência perdida.

\subsection{Caracterização dos agregados}

Inicialmente, buscou-se conhecer a qualidade dos agregados empregados atualmente na produção de blocos. Os agregados foram submetidos a ensaios para determinação das suas características físicas. Os resultados estão na Tabela 3.

Tabela 3. Características físicas dos agregados.

\begin{tabular}{llcc}
\hline \multicolumn{1}{c}{ Ensaio } & Norma ABNT & $\begin{array}{c}\text { Agregado } \\
\text { miúdo }\end{array}$ & $\begin{array}{c}\text { Agregado } \\
\text { graúdo }\end{array}$ \\
\hline $\begin{array}{l}\text { Dimensão Máxima } \\
\text { Característica - DMC }\end{array}$ & NBR NM 248/01 [11] & $4,75 \mathrm{~mm}$ & $9,50 \mathrm{~mm}$ \\
\hline Módulo de Finura - MF & NBR NM 248/01 [11] & 3,11 & 5,89 \\
\hline $\begin{array}{l}\text { Massa unitária de } \\
\text { material no estado solto }\end{array}$ & NBR NM 45/06 [12] & $1,74 \mathrm{~kg} / \mathrm{dm}^{3}$ & $1,5 \mathrm{~kg} / \mathrm{dm}^{3}$ \\
\hline $\begin{array}{l}\text { Teor de umidade total } \\
\text { Índice de forma pelo } \\
\text { método do paquímetro }\end{array}$ & NBR 7809/06 [14] & - & Dispenso \\
\hline
\end{tabular}

Ainda para caracterização dos agregados, realizou-se a granulometria por peneiramento da areia. A distribuição granulométrica do agregado miúdo pode ser vista na Figura 4, bem como os limites da zona considerada ótima e da zona utilizável.

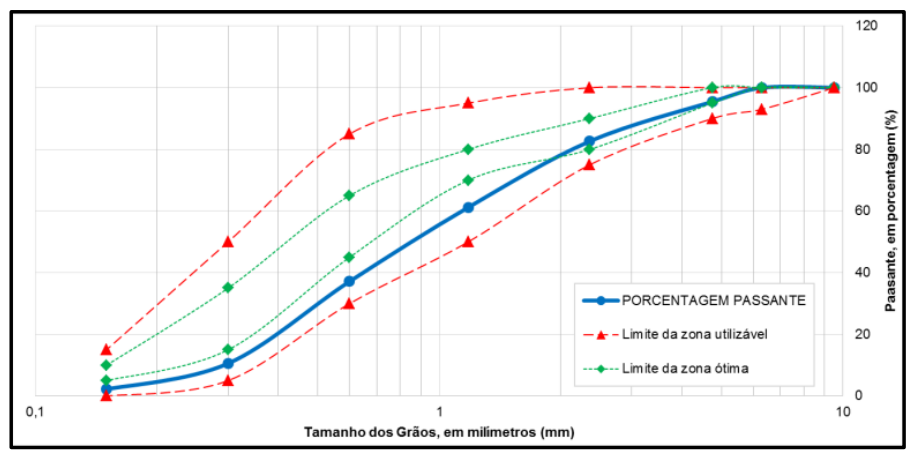

Figura 4 - Curva granulométrica do agregado miúdo.

Com base nas curvas granulométricas ilustradas no gráfico da Figura 4, é possível verificar a insuficiência de finos na composição deste agregado, caracterizando um material constituído de grãos de dimensão maiores. Consequentemente, haverá maior quantidade de vazios presentes no concreto, interferindo na resistência à compressão.
A granulometria do pedrisco também foi realizada. $\mathrm{Na}$ Figura 5, pode-se visualizar a distribuição granulométrica do agregado graúdo, bem como a zona granulométrica de menor e maior dimensão do agregado graúdo, sendo atribuídas as curvas correspondentes para a verificação do limite da zona granulométrica.

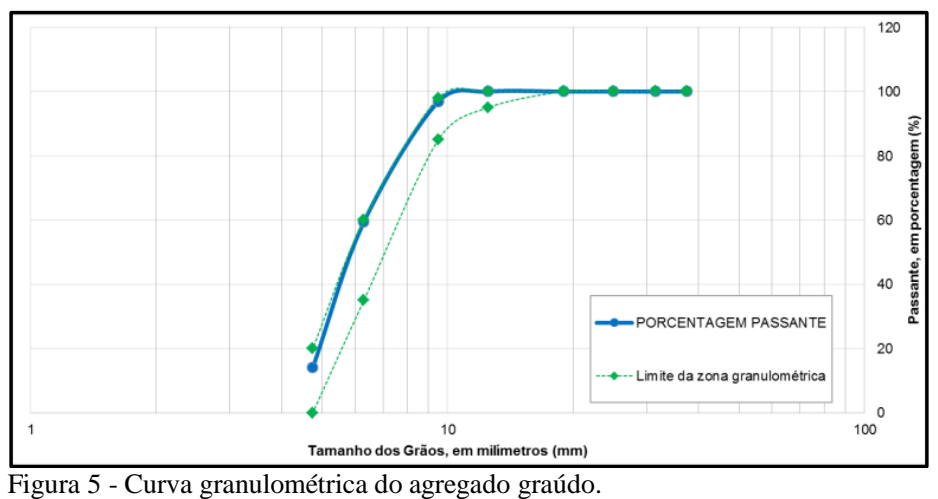

Figura 5 - Curva granulométrica do agregado graúdo.

A Figura 5 mostra a zona correspondente ao agregado denominado como brita 0 , com diâmetro menor em 4,75 mm e maior em 12,5 mm. A predominância caracterizou-se pela presença de agregados de menor dimensão na composição, tendo maiores quantidades de passantes em cada peneira, contudo dentro dos limites admissíveis.

$\mathrm{O}$ ensaio de índice de forma do agregado graúdo, regido pela NBR 7809/06 [14], estabelece que se devam desprezar as frações passantes na peneira de abertura de malha $9,5 \mathrm{~mm}$ e as que obtiverem porcentagem individual inferiores a $5 \%$. Sendo assim, descartando os resultados do material passante na peneira $9,5 \mathrm{~mm}$, e obtendo somente o retido na peneira $9,5 \mathrm{~mm}$, resulta em uma porcentagem inferior a $5 \%$, desconsiderando-se, nesta situação, o método de ensaio.

\subsection{Dosagem do traço}

Considerando-se o método do menor volume de vazios, tomando como base a massa unitária do agregado, ensaiaramse diferentes proporções de massas de misturas de pedrisco e areia, que foram compactados em um recipiente de volume conhecido. A Figura 6 ilustra a sequência dos procedimentos adotados durante o ensaio, a fim de determinar o grau de variação de massa dos agregados que caibam no recipiente. A proporção ideal será definida no instante em que a quantidade de agregado miúdo for o suficiente para preencher os vazios existentes entres os grãos do agregado graúdo, observada pela maior massa obtida da relação dos agregados. 


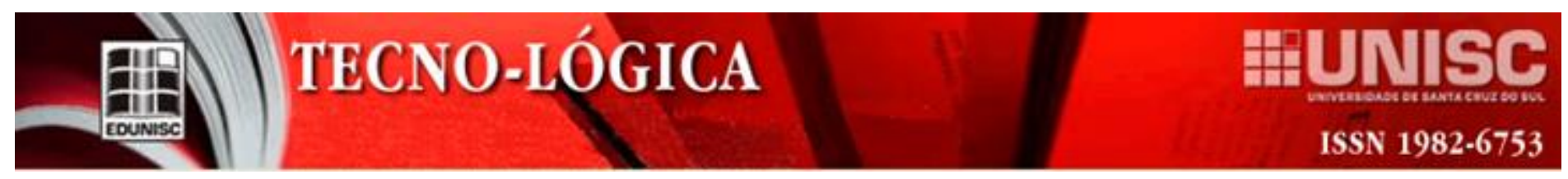

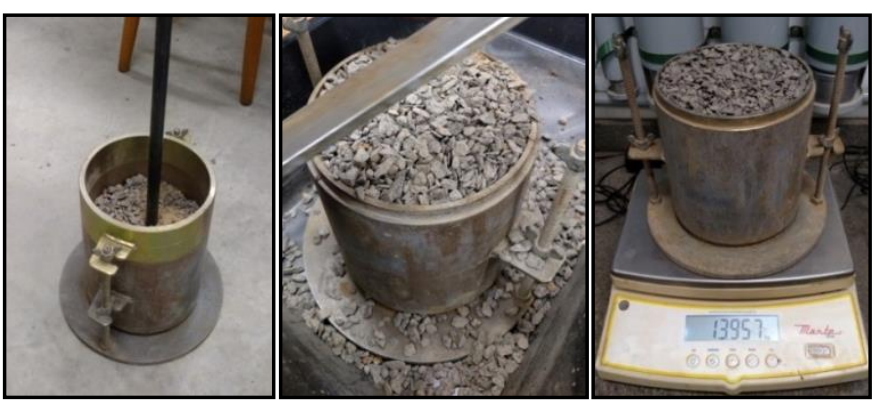

Figura 6 - Ensaio do método de melhor proporção pedrisco/areia.

A Tabela 4 apresenta a relação de diferentes proporções de agregados graúdos e miúdos submetidas à realização do ensaio, bem como os resultados obtidos para a massa unitária do agregado.

Tabela 4. Resultado do ensaio do menor volume de vazios.

\begin{tabular}{cc}
\hline $\begin{array}{c}\text { Proporção Pedrisco / Areia } \\
\text { \% }\end{array}$ & $\begin{array}{c}\text { Massa Unitária do Agregado } \\
\mathbf{k g} / \mathbf{c m}^{\mathbf{3}}\end{array}$ \\
\hline $100 / 0$ & 1,6724 \\
$90 / 10$ & 1,7872 \\
$80 / 20$ & 1,9060 \\
$70 / 30$ & 1,9909 \\
$60 / 40$ & 2,0646 \\
$\mathbf{5 0 / 5 0}$ & $\mathbf{2 , 1 0 9 5}$ \\
$40 / 60$ & 2,0984 \\
$30 / 70$ & 2,0836 \\
\hline
\end{tabular}

Com os resultados da Tabela 4, é possível verificar a proporção pedrisco/areia que resulta na maior massa unitária do agregado. Portanto, a proporção $50 \%$ de pedrisco e $50 \%$ de areia é considerada a relação de mistura ideal pelo método. Entretanto, considerando a média de preços comerciais de brita 0 e areia grossa na região, é economicamente mais viável reduzir a quantidade de areia. Outro fator determinante é a areia apresentar maior superfície de contato, necessitando maiores quantidade de aglomerante para envolver os grãos

Considerando os estudos de traços realizados em experimentos de outros autores, buscou-se embasamento em resultados de resistência característica aos 28 dias acima de 35 $\mathrm{MPa}$, conforme exigido para tráfego de pedestres, veículos leves e veículos comerciais de linha. Quanto aos aglomerantes empregados, todos os autores utilizaram em seus experimentos o cimento CP V-ARI [8]; somente Vargas (2002) usou o cimento CP II-Z-32. A Tabela 5 mostra os resultados obtidos por esses autores.

Analisando os dados e parâmetros obtidos nos ensaios realizados pelos autores consultados, aliado aos materiais disponíveis e considerando um traço econômico, fixaram-se os traços de dosagem apresentados na Tabela 6.

Os traços foram misturados em betoneira disponível na fábrica e realizou-se lançamento manual para o silo de concreto na parte superior da vibro-prensa. A quantidade determinada para cada mistura foi o dobro do necessário para a fabricação de uma tábua compondo 12 unidades de pavers, sendo descartada a sobra de concreto. Na Figura 7, é possível visualizar as etapas de lançamento do concreto pelo silo superior, com vibração da mesa para espalhamento e distribuição adequada nas fôrmas, seguida de prensagem dos blocos e conclusão dos mesmos.

$\mathrm{O}$ procedimento de cura adotado foi o comumente empregado pela fábrica, que consiste no armazenamento dos blocos em área coberta e realização de molhagem com água corrente nas primeiras horas após a moldagem e outra após, aproximadamente, 18 horas. Nesse procedimento ocorrem alterações de cura com as variações climáticas.

Tabela 5. Pesquisa bibliográfica de traços experimentais. (Elaborado pelo Autor, 2017, com base em dados de Machado [15], Hood [3], Vargas [16], Cruz [5] e Santos [17]).

\begin{tabular}{|c|c|c|c|c|c|c|c|c|}
\hline $\begin{array}{c}\text { Identificação } \\
\text { do traço }\end{array}$ & $\begin{array}{c}\text { Cimento } \\
\mathrm{Kg}\end{array}$ & $\begin{array}{c}\text { Areia média } \\
\mathrm{Kg}\end{array}$ & $\begin{array}{c}\text { Areia fina } \\
\text { kg }\end{array}$ & $\begin{array}{c}\text { Pedrisco } \\
\text { kg }\end{array}$ & $\begin{array}{c}\text { Total de agregados } \\
\text { kg }\end{array}$ & Relação a/c & Teor de argamassa $(\alpha)$ & $\begin{array}{c}\text { Resist. à compr. } 28 \text { dias } \\
\text { MPa }\end{array}$ \\
\hline MACHADO [15] & 1 & 2,27 & 1,27 & 0,91 & 4,45 & 0,31 & 0,83 & 39,60 \\
\hline HOOD [3] & 1 & 2,67 & 0,67 & 1,16 & 4,50 & 0,37 & 0,79 & 38,64 \\
\hline VARGAS [16] & 1 & 1,69 & 2,42 & 1,02 & 5,13 & 0,42 & 0,83 & 37,00 \\
\hline CRUZ [5] & 1 & 2,50 & 0,83 & 1,08 & 4,41 & 0,31 & 0,80 & 36,90 \\
\hline SANTOS [17] & 1 & 1,71 & 0,93 & 1,17 & 3,81 & 0,35 & 0,76 & 36,74 \\
\hline
\end{tabular}

Tabela 6. Determinação dos traços estudados.

\begin{tabular}{|c|c|c|c|c|c|c|}
\hline $\begin{array}{c}\text { Identif. } \\
\text { do }\end{array}$ & Cimento & Areia & Pedrisco & $\begin{array}{c}\text { Total de } \\
\text { agregados }\end{array}$ & $\mathbf{a} / \mathbf{c}$ & $\begin{array}{c}\text { Teor de } \\
\text { argamassa }\end{array}$ \\
\hline Traço & kg & Kg & kg & kg & & $(\alpha)$ \\
\hline 1 & 1 & 2,00 & 2,00 & 4,00 & 0,30 & 0,60 \\
\hline 2 & 1 & 2,00 & 2,00 & 4,00 & 0,34 & 0,60 \\
\hline 3 & 1 & 2,50 & 2,50 & 5,00 & 0,30 & 0,58 \\
\hline 4 & 1 & 2,50 & 2,50 & 5,00 & 0,34 & 0,58 \\
\hline 5 & 1 & 3,00 & 1,00 & 4,00 & 0,30 & 0,80 \\
\hline 6 & 1 & 3,00 & 1,00 & 4,00 & 0,34 & 0,80 \\
\hline 7 & 1 & 3,75 & 1,25 & 5,00 & 0,30 & 0,79 \\
\hline 8 & 1 & 3,75 & 1,25 & 5,00 & 0,34 & 0,79 \\
\hline
\end{tabular}

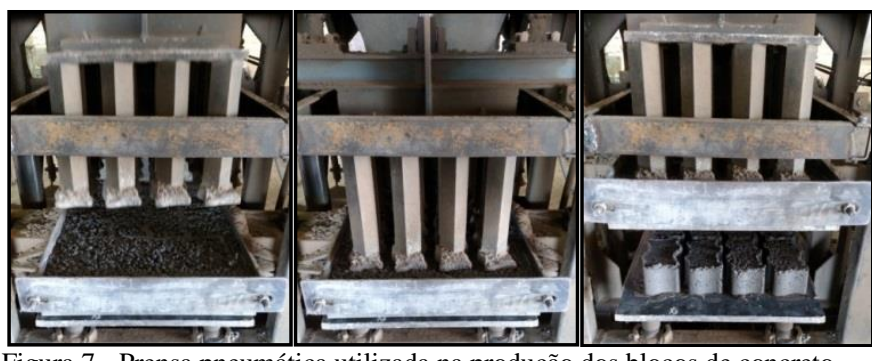

Figura 7 - Prensa pneumática utilizada na produção dos blocos de concreto. 


\subsection{Ensaios nos blocos pré-moldados de concreto}

Após o período de cura, as amostras foram retiradas aleatoriamente e identificadas para serem submetidas aos ensaios, conforme a Tabela 7. Por ser facultativo, o ensaio de resistência à abrasão não foi realizado neste estudo.

Tabela 7. Amostragem para ensaio. (NBR 9781/13 [1]).

\begin{tabular}{lc}
\multicolumn{1}{c}{ Propriedade } & Quantidade de amostras \\
\hline Inspeção visual & $6^{*}$ \\
Avaliação dimensional & $6^{*}$ \\
Absorção de água & 3 \\
Resistência à compressão & 6 \\
Resistência à abrasão & $3^{* *}$ \\
\hline${ }^{*}$ As peças amostradas podem ser utilizadas também para os ensaios de \\
resistência à compressão ou abrasão. \\
${ }^{* *}$ Ensaio facultativo.
\end{tabular}

\section{Apresentação e análise dos resultados}

\subsection{Ensaios aplicados nos blocos de dosagem inicial}

As amostras passaram por uma análise técnica visual, ressaltando os critérios requeridos pela NBR 9781/13 [1]. A amostra identificada como "P", foi coletada aleatoriamente de um lote produzido pela fábrica da Prefeitura Municipal, com o intuito de realizar uma análise das atuais condições em que se encontravam os blocos. A Figura 8 ilustra os blocos confeccionados e analisados no estudo.

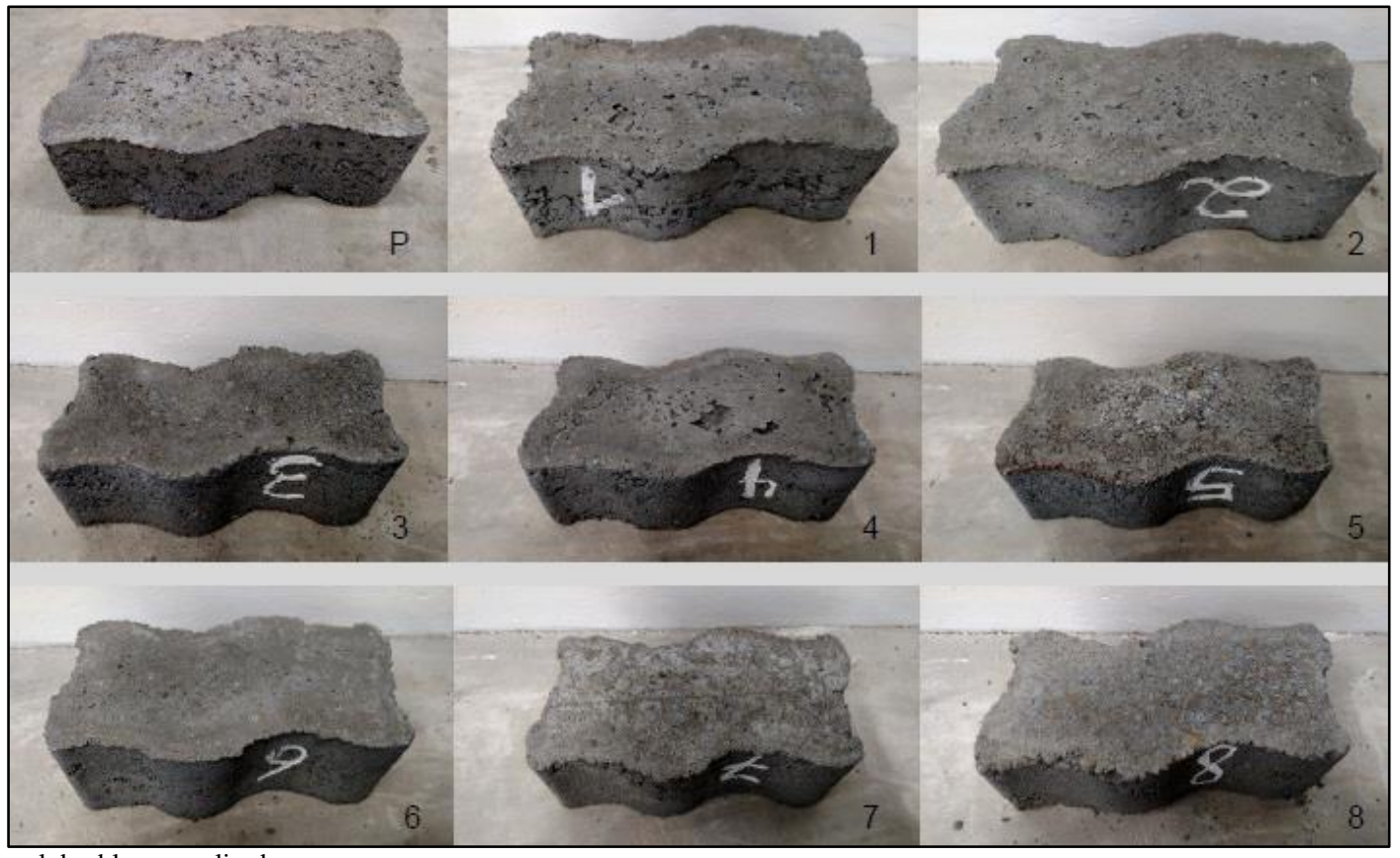

Figura 8 - Aspecto visual dos blocos analisados.

Com o intuito de obter um traço consideravelmente econômico, reduzindo a adição de cimento, a amostra "P" produzida pela equipe da Prefeitura apresenta alto índice de vazios, em decorrência de um traço fraco, com insuficiência de pasta de cimento. Considerando os traços com presença maior de agregado miúdo, houve uma melhora no acabamento, havendo menores vazios ou falhas no concreto. Estes vazios afetam a durabilidade da peça, assim como ocorre uma diminuição na resistência.

O emprego de uma vibro-prensa com vida útil elevada causa desgastes no contato forma-prensa, ocorrendo presença de rebarba na parte inferior e superior, sendo mais acentuada quanto maior for a relação a/c (água/cimento). Os cantos irregulares, ou com presença de rebarba, comprometem o correto assentamento e travamento das peças no pavimento. A Tabela 8 apresenta o resultado médio (M) e o desvio padrão (s) obtidos nos ensaios de avaliação dimensional, absorção de água e resistência característica à compressão aos 28 dias.

De acordo com a Tabela 8, pode-se concluir que o comprimento e a largura dos blocos se enquadram nas dimensões e tolerâncias impostas pela Norma, considerando comprimento nominal máximo de $250 \mathrm{~mm}$ e largura real de no mínimo $97 \mathrm{~mm}$. Quanto à espessura das peças, devem ter uma dimensão mínima de $60 \mathrm{~mm}$ e apresentar múltiplos de $20 \mathrm{~mm}$; porém, os resultados obtidos demostram uma espessura próxima de $75 \mathrm{~mm}$, tornando os blocos sem padronização 
quanto ao estabelecido em Norma. Avaliando estes parâmetros, os blocos produzidos na fábrica são impróprios para uso, pois a vibro-prensa foi regulada com espessura menor do que o exigido.

Ainda analisando os resultados da Tabela 8, pode-se verificar um melhor desempenho da absorção nos traços identificados como 2, 4 e 6. A variação da relação a/c, ou seja, da quantidade de água inserida no traço, teve grande influência na absorção, devido à insuficiência de água para hidratação do cimento. Os traços identificados como P, 7 e 8 não atenderam o limite de absorção médio, comprometendo sua durabilidade. Esta alta absorção de água é explicada devido à alta quantidade de vazios entre os grãos, decorrente da falta de agregados finos para preenchimentos dos vazios existentes, aliado à falta de pasta de cimento para envolver os agregados.

Tabela 8. Resultado da avaliação dimensional, absorção de água e resistência característica à compressão dos blocos.

\begin{tabular}{|c|c|c|c|c|c|c|c|c|}
\hline \multirow[t]{2}{*}{$\begin{array}{l}\text { Identif. } \\
\text { do traço }\end{array}$} & \multicolumn{8}{|c|}{ 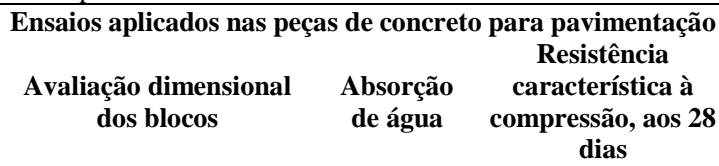 } \\
\hline & Méc & (M) & $\mathbf{s}$ & M & $\mathbf{s}$ & M & $f_{-}$ & $\mathbf{s}$ \\
\hline P & $\begin{array}{c}\text { Comp. } \\
\text { Larg. } \\
\text { Esp. }\end{array}$ & $\begin{array}{c}201,24 \\
100,69 \\
74,63\end{array}$ & $\begin{array}{l}0,92 \\
0,97\end{array}$ & 6,45 & $\begin{array}{c}0,3 \\
2\end{array}$ & 18,14 & 15,62 & 2,74 \\
\hline 1 & $\begin{array}{c}\text { Comp. } \\
\text { Larg. } \\
\text { Esp. }\end{array}$ & $\begin{array}{c}200,66 \\
99,31 \\
73,67 \\
\end{array}$ & 0 , & 3,42 & $\begin{array}{c}0,9 \\
8\end{array}$ & 22,57 & 20,06 & 2,72 \\
\hline 2 & $\begin{array}{l}\text { Comp. } \\
\text { Larg. } \\
\text { Esp. }\end{array}$ & $\begin{array}{c}200,61 \\
99,92 \\
75,51\end{array}$ & $\begin{array}{l}0,66 \\
0,96 \\
1,59\end{array}$ & 3,21 & $\begin{array}{c}0,0 \\
3\end{array}$ & 30,33 & 29,07 & 1,36 \\
\hline 3 & $\begin{array}{l}\text { Comp. } \\
\text { Larg. } \\
\text { Esp. }\end{array}$ & $\begin{array}{c}200,86 \\
98,16 \\
76,80\end{array}$ & $\begin{array}{l}1,29 \\
0,99 \\
0,63\end{array}$ & 4,22 & $\begin{array}{c}1,1 \\
3\end{array}$ & 19,30 & 5,45 & 4,18 \\
\hline 4 & $\begin{array}{l}\text { Comp. } \\
\text { Larg. } \\
\text { Esp. }\end{array}$ & $\begin{array}{c}200, \\
100, \\
75,\end{array}$ & $\begin{array}{l}0,76 \\
0,33 \\
1,83 \\
\end{array}$ & 3,00 & $\begin{array}{c}0,8 \\
0\end{array}$ & 32,07 & 9,31 & 3,00 \\
\hline 5 & $\begin{array}{l}\text { Comp. } \\
\text { Larg. } \\
\text { Esp. }\end{array}$ & $\begin{array}{c}200,33 \\
99,32 \\
74,08\end{array}$ & $\begin{array}{l}0,58 \\
0,87 \\
0,86\end{array}$ & 4,57 & $\begin{array}{c}0,6 \\
8\end{array}$ & 29,20 & 24,68 & 4,92 \\
\hline 6 & $\begin{array}{c}\text { Comp. } \\
\text { Larg. } \\
\text { Esp. }\end{array}$ & $\begin{array}{c}201,08 \\
99,71 \\
75,45 \\
\end{array}$ & $\begin{array}{l}0,78 \\
0,78 \\
0,87 \\
\end{array}$ & 3,22 & $\begin{array}{c}0,7 \\
1\end{array}$ & 31,28 & 27,83 & 3,75 \\
\hline 7 & $\begin{array}{c}\text { Comp. } \\
\text { Larg. } \\
\text { Esp. }\end{array}$ & $\begin{array}{c}200,83 \\
99,64 \\
76,56 \\
\end{array}$ & $\begin{array}{l}0,37 \\
0,57 \\
0,75 \\
\end{array}$ & 6,47 & $\begin{array}{c}0,6 \\
9\end{array}$ & 14,82 & 13,19 & 1,78 \\
\hline 8 & $\begin{array}{c}\text { Comp. } \\
\text { Larg. } \\
\text { Esp. }\end{array}$ & $\begin{array}{c}201,29 \\
98,80 \\
74,80 \\
\end{array}$ & $\begin{array}{l}0,44 \\
0,86 \\
0,58 \\
\end{array}$ & 6,18 & $\begin{array}{c}1,1 \\
5\end{array}$ & 10,74 & 8,88 & 2,03 \\
\hline
\end{tabular}

Considerando a importância da resistência à compressão das peças na durabilidade do pavimento, e verificando a Tabela 8, foram obtidos melhores desempenhos nos traços identificados como 2, 4 e 6 . A relação a/c maior nestes traços teve grande influência na hidratação do cimento, originando melhor desempenho. Vale destacar que o traço da prefeitura, embora não tenha tido o pior desempenho entre os estudados, não chegou nem perto da resistência de $35 \mathrm{MPa}$

\subsection{Alterações na confecção dos blocos}

Com o intuito de aprimorar os resultados dos ensaios iniciais, buscou-se analisar os resultados de inspeção visual, absorção de água e, primeiramente, resistência à compressão dos blocos. Optou-se por selecionar 2 traços que demostraram melhor desempenho e eficiência, dentre os já estudados neste trabalho. Os traços identificados como 4 e 6 apresentaram menor absorção de água, indicando menor quantidade de vazios, tornando a resistência à compressão maior e contribuindo para maior durabilidade do pavimento. $\mathrm{O}$ aspecto visual destas amostras também foi um fator determinante, ou seja, menor quantidade de falhas em meio ao concreto. Com os dois traços selecionados serão confeccionados novos blocos pré-moldados de concreto, alterando o agregado miúdo e o cimento empregado.

Procurou-se alterar o agregado miúdo, pois o mesmo teve indicativo de falta de finos na sua composição granulométrica. Esta modificação tem pouca implicação no custo do traço definido, porém, contribui para selar os vazios entre grãos e melhorar o aspecto visual dos blocos.

Com o objetivo de obter alta resistência inicial, encurtando o processo de cura dos blocos e promovendo a implantação mais rápida de ruas, adotou-se o uso de cimento CPV-ARI [8] para fins comparativos, visto que vários autores consultados na literatura empregaram este cimento nos seus traços. Este cimento é fabricado pelo Grupo Votorantim Cimentos, apresentando secagem ultrarrápida e ultrarresistência.

Considerando os parâmetros descritos anteriormente, a Tabela 9 apresenta os traços identificados como 4A e 6A, com dosagem aplicada em massa.

Tabela 9. Determinação do melhoramento de traço

\begin{tabular}{|c|c|c|c|c|c|c|c|}
\hline \multirow{2}{*}{$\begin{array}{c}\text { Ident. } \\
\text { do } \\
\text { Traço }\end{array}$} & \multicolumn{2}{|c|}{ Cimento } & \multirow{2}{*}{$\begin{array}{c}\text { Areia } \\
\text { kg }\end{array}$} & \multirow{2}{*}{$\begin{array}{c}\text { Pedrisco } \\
\text { kg }\end{array}$} & \multirow{2}{*}{$\begin{array}{c}\text { Total de } \\
\text { agregado } \\
\text { s } \\
\text { kg }\end{array}$} & \multirow[t]{2}{*}{$\mathbf{a} / \mathbf{c}$} & \multirow{2}{*}{$\begin{array}{c}\text { Teor de } \\
\text { argamass } \\
\quad \text { a }(\alpha)\end{array}$} \\
\hline & Tipo & kg & & & & & \\
\hline $4 A$ & $\begin{array}{c}\text { CPV- } \\
\text { ARI }\end{array}$ & 1 & 2,50 & 2,50 & 5,00 & $\begin{array}{c}0,3 \\
2\end{array}$ & 0,58 \\
\hline $6 A$ & $\begin{array}{c}\text { CPV- } \\
\text { ARI }\end{array}$ & 1 & 3,00 & 1,00 & 4,00 & $\begin{array}{c}0,3 \\
2\end{array}$ & 0,80 \\
\hline
\end{tabular}

A adição de água foi feita gradativamente, controlando a quantidade e verificando a consistência do concreto. Desta forma, chegou-se a uma relação a/c de 0,32 para ambos os traços. A umidade dos agregados no momento da dosagem é um fator decisivo na adição de água, constituindo uma variável na determinação do traço. 


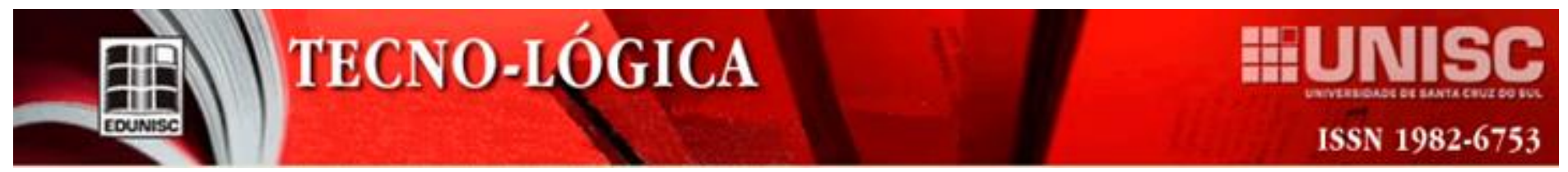

O agregado miúdo adotado no aprimoramento dos blocos tem procedência de uma extração do Rio Jacuí/RS. O aspecto da areia pode ser visualizado na Figura 9.

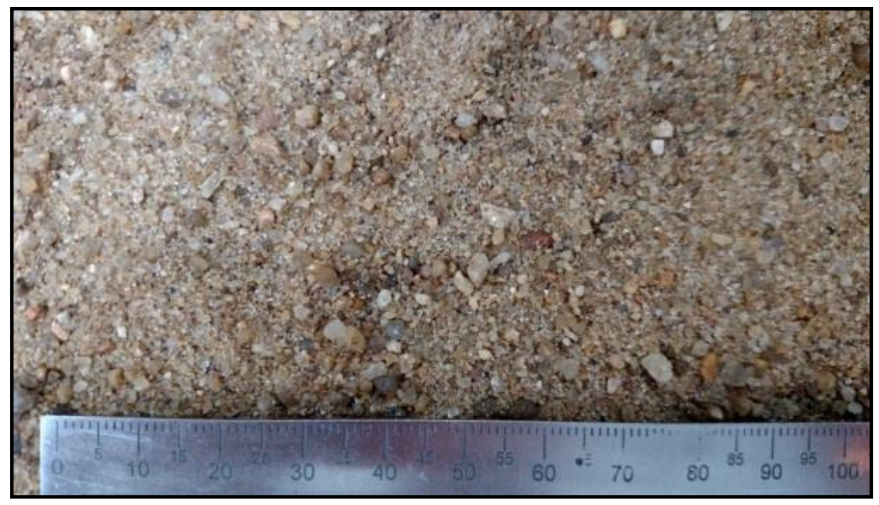

Figura 9 - Aspecto visual do novo agregado miúdo.

Para determinação das características da areia adotada para os novos testes, realizou-se a granulometria por peneiramento, massa unitária e teor de umidade total natural no momento da dosagem do concreto. A Tabela 10 apresenta as características físicas dos novos agregados utilizados.

Tabela 10. Definição das características físicas dos novos agregados.

\begin{tabular}{lccc}
\hline \multicolumn{1}{c}{ Ensaio } & Norma ABNT & $\begin{array}{c}\text { Agregado } \\
\text { miúdo }\end{array}$ & $\begin{array}{c}\text { Agregado } \\
\text { graúdo }\end{array}$ \\
\hline $\begin{array}{l}\text { Dimensão Máxima } \\
\text { Característica - DMC }\end{array}$ & NBR NM 248/01 [11] & $2,36 \mathrm{~mm}$ & $9,50 \mathrm{~mm}$ \\
\hline Módulo de Finura - MF & NBR NM 248/01 [11] & 2,44 & 5,89 \\
\hline $\begin{array}{l}\text { Massa unitária de } \\
\text { material no estado solto }\end{array}$ & NBR NM 45/06 [12] & $1,58 \mathrm{~kg} / \mathrm{dm}^{3}$ & $1,5 \mathrm{~kg} / \mathrm{dm}^{3}$ \\
\hline $\begin{array}{l}\text { Teor de umidade total } \\
\text { Indice de forma pelo } \\
\text { método do paquímetro }\end{array}$ & NBR 7809/06 [14] & - & Dispenso \\
\hline
\end{tabular}

Na Figura 10, apresenta-se o resultado do ensaio de granulometria por peneiramento realizado com a areia.

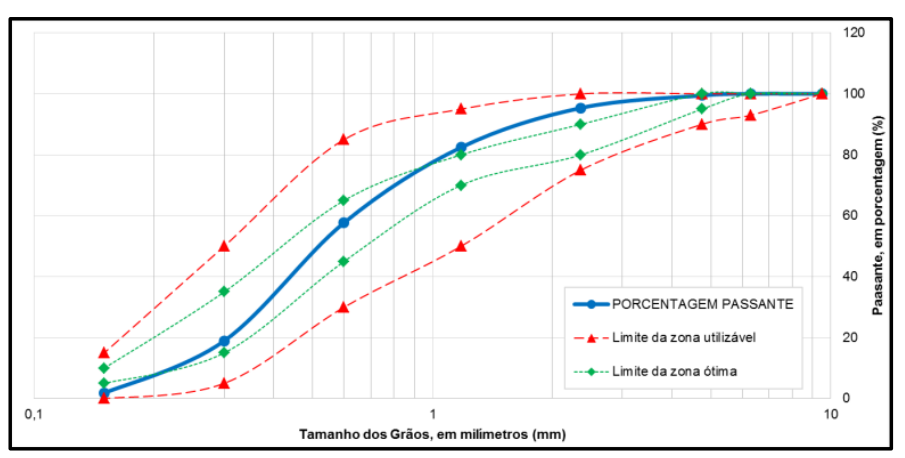

Figura 10 - Curva granulométrica do novo agregado miúdo.
Analisando a Figura 10, verifica-se que houve grande modificação na composição do agregado miúdo, sendo constituído de maior quantidade de grãos finos. Este fator proporcionará preencher os vazios entre os agregados graúdos, aumentando, assim, a resistência das peças.

\subsection{Ensaios aplicados nos novos blocos}

$\mathrm{O}$ aspecto visual dos novos blocos confeccionados foi analisado verificando o acabamento, detectando possíveis defeitos ou imperfeições que pudessem comprometer a estrutura de intertravamento ou estética do pavimento. A Figura 11 ilustra a aparência de cada bloco com seu respectivo traço.

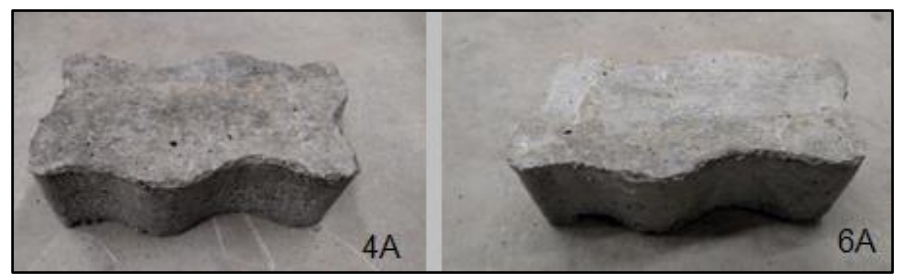

Figura 11 - Inspeção visual.

Os traços identificados como 6A e 6B apresentam em suas constituições maiores quantidades de agregado miúdo, favorecendo uma superfície mais regular e lisa. $\mathrm{O}$ resultado médio (M) e o desvio padrão (s) da avaliação dimensional, absorção de água e resistência característica à compressão dos blocos podem ser visualizados na Tabela 11.

Tabela 11. Resultado da avaliação dimensional, absorção de água e resistência característica à compressão dos blocos.

\begin{tabular}{|c|c|c|c|c|c|c|c|c|}
\hline \multirow{3}{*}{$\begin{array}{l}\text { Identif. } \\
\text { do traço }\end{array}$} & \multicolumn{8}{|c|}{ Ensaios aplicados nas peças de } \\
\hline & \multicolumn{3}{|c|}{$\begin{array}{l}\text { Avaliação dimensional } \\
\text { dos blocos }\end{array}$} & \multicolumn{2}{|c|}{$\begin{array}{l}\text { Absorção } \\
\text { de água }\end{array}$} & \multicolumn{3}{|c|}{$\begin{array}{c}\text { Resistência } \\
\text { característica à } \\
\text { compressão, aos } 28 \\
\text { dias }\end{array}$} \\
\hline & Méd & (M) & $\mathbf{s}$ & M & $\mathbf{s}$ & $\mathbf{M}$ & $\mathbf{f}_{\mathrm{pk}, \mathrm{est} .}$ & $\mathbf{s}$ \\
\hline \multirow{3}{*}{$P$} & Comp. & 201,6 & 0,85 & & & & & \\
\hline & Larg. & 101,57 & 1,06 & 3,25 & $\begin{array}{c}0,1 \\
2\end{array}$ & 43,69 & 40,31 & 3,68 \\
\hline & Esp. & 75,11 & 1,41 & & & & & \\
\hline \multirow{3}{*}{1} & Comp. & 200,90 & 1,32 & \multirow{3}{*}{4,32} & \multirow{3}{*}{$\begin{array}{c}0,1 \\
8\end{array}$} & \multirow{3}{*}{33,11} & \multirow{3}{*}{30,15} & \multirow{3}{*}{3,21} \\
\hline & Larg. & 102,15 & 0,39 & & & & & \\
\hline & Esp. & 75,72 & 0,68 & & & & & \\
\hline
\end{tabular}

A avaliação dimensional dos blocos verificada na Tabela 11 apresentou adequadas dimensões no comprimento e na largura, com medidas próximas de $200 \mathrm{~mm}$ e $100 \mathrm{~mm}$, respectivamente, e sem registro de variações maiores de $3 \mathrm{~mm}$, toleradas pela NBR 9781/13 [1]. Analisando a espessura do bloco, nota-se a despadronização da dimensão, sendo que o recomendado para tráfego pequeno e médio é no mínimo $80 \mathrm{~mm}$, e medidas em múltiplos de $20 \mathrm{~mm}$. No caso dos blocos produzidos, foram obtidos valores próximos a $75 \mathrm{~mm}$, estando desadequado para uso em ruas urbanas do Município. Portanto, 
é necessária uma adequação na regulagem da espessura, visto que, a vibro-prensa possibilita ajuste de altura dos blocos.

Ainda observando os dados da Tabela 11, o traço identificado como 4A, apresentou a menor absorção de água e teve a maior resistência característica à compressão. Ao realizar uma análise geral de todos os traços, as amostras com cimento CPV-ARI [8] tiveram melhor desempenho entre os analisados.

Importante destacar que os traços propostos neste estudo apresentaram resistência mais adequada, conforme exigência normativa, do que o traço atualmente empregado pela Prefeitura Municipal na confecção dos blocos para pavimentação. Isso demostra que é fundamental realizar o controle tecnológico da confecção das peças para garantir uma maior qualidade no produto fabricado.

\section{Conclusões}

O presente trabalho teve como objetivo principal dosar um traço de concreto adequado, de forma a atender os critérios estabelecidos pela NBR 9781/13 [1], utilizando os equipamentos e materiais disponíveis na fábrica da Secretaria Municipal de Obras de um município do Rio Grande do Sul. O processo de dosagem utilizado atualmente, com os agregados medidos em volume e a adição de água a critério do operador, torna o traço impreciso, sujeito a variações e compromete o aspecto visual e a resistência à compressão dos blocos. Outro fator relevante é o estado de conservação dos equipamentos, sem procedimentos de manutenção e prevenção, aliado ao desgaste natural do uso diário. Manter os equipamentos em constante manutenção preventiva e calibragem, é de caráter fundamental para tornar o processo mais eficiente.

A vibro-prensa é operada por procedimentos manuais controlados pelo operador, ocasionando variações de tempo na vibração e prensagem. Isto é refletido nas variações de resultados, sendo importante a adoção de processos automatizados. As calibrações do alinhamento das chapas de prensagem influenciam a prensagem homogênea de cada bloco, ocorrendo diferenças prejudiciais de prensagem entre os 12 blocos de cada ciclo de produção. Considerando os resultados da avaliação dimensional dos blocos, é importante destacar a adoção inadequada da espessura, devido à regulagem da prensa. Aos critérios da NBR 9781/13 [1], o descumprimento das dimensões e tolerâncias das peças, resulta na rejeição do lote dos blocos.

O método de compra de materiais adotado impossibilita uma análise técnica da qualidade dos materiais, pois o processo se dá por licitação, critério de compra de materiais em órgão público, que valida o critério de menor preço, normalmente independente da qualidade dos agregados. Este procedimento, por exemplo, não poderia evitar a compra do agregado graúdo com presença de grãos lamelares, indesejáveis na produção de um concreto de melhor qualidade e eficiência. No caso do agregado miúdo, recomenda-se escolher a melhor distribuição granulométrica, com a realização de ensaios em laboratório e análise técnica.

Destaca-se a importância de conhecer as característica e propriedades dos materiais na composição do concreto, que implicam diretamente na capacidade final das peças. O controle de qualidade na produção do concreto é fundamental para a produção dos blocos, como verificado no decorrer deste estudo. Ressalta-se que os traços propostos neste trabalho apresentaram melhores desempenhos às exigências normativas, se comparado ao traço adotado atualmente pela Prefeitura Municipal na fabricação de blocos para pavimentação. Isso é observado na absorção de água e na resistência à compressão, além do melhor aspecto visual dos blocos.

A adoção do traço 4A com cimento CP V - ARI [8] promoveu um melhor desempenho na capacidade de resistência à compressão final do bloco. Ao realizar uma análise comparativa do traço 4A, confeccionado com 1:5 (cimento:agregado), com os blocos fabricados pela Prefeitura Municipal de proporção 1:7,25 (cimento:agregado), obteve-se um ganho superior a $158 \%$ na resistência à compressão. Este aumento significativo tem relação com a importância do estudo das propriedades dos materiais e da dosagem do concreto na produção dos blocos pré-fabricados.

\section{PROPOSED MIXTURE FOR INTERLOCKING CONCRETE PAVING BLOCKS}

ABSTRACT: The present paper presents a technical study of concrete mixtures for application in interlocking concrete paving blocks, promoting tests to determine the characteristics and properties of the aggregates, such as analysis of the granulometric composition, unit mass of material in the loose state and total moisture content. The main objective of this paper is to evaluate experimental dosages of concrete mixtures, varying the addition of water and different amounts and proportions of small and large aggregates, trying to understand their influences. Another parameter to be analyzed is the influence of the type of cement in the mixture. To verify these, the blocks were submitted to tests of visual inspection, dimensional evaluation, water absorption and characteristic resistance to compression. This study can justify the fundamental importance of technological control when manufacturing the pieces, to achieve a final product with better quality. It was also possible to compare the cost-benefit of the blocks made in the study, with the blocks currently manufactured in the city factory. The results show the best performance of the proposed concrete mixtures, verifying the influence of material parameters, vibro-press and dosage. Finally, a technically more adequate dosage was proposed to be 


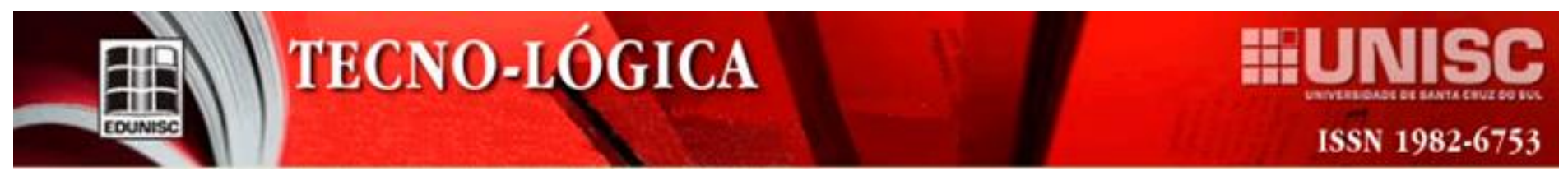

used in the city factory for the production of interlocking concrete paving blocks.

Keywords: Pavement. Interlocking Concrete Paving Blocks. Concrete Mixtures.

\section{Referências}

[1] Associação Brasileira de Normas Técnicas - ABNT. Norma Brasileira Regulamentadora - NBR. NBR 9781: 2013 - Peças de concreto para pavimentação: Especificação e métodos de ensaio. 2. ed. 21 p. Rio de Janeiro: ABNT, 2013.

[2] SOUZA, André M. L. de. Pavimentação com blocos intertravados de concreto: análise crítica da técnica de execução. Jun. 2013. 75 f. Trabalho de Diplomação (Curso de Engenharia Civil) - Universidade Federal do Rio Grande do Sul - UFRGS, Porto Alegre, RS, 2013.

[3] HOOD, Rogério da Silva S. Análise da viabilidade técnica da utilização de resíduos de construção e demolição como agregado miúdo reciclado na confecção de blocos de concreto para pavimentação. Nov. 2006. 150 f. Dissertação de Mestrado (Programa de Pós-Graduação em Engenharia Civil) Universidade Federal do Rio Grande do Sul - UFRGS, Porto Alegre, RS, 2006.

[4] FIORITI, Cesar F. Pavimentos intertravados de concreto utilizando resíduos de pneus como material alternativo. 2007. 218 f. Tese de Doutorado (Curso de Ciências da Engenharia Ambiental - Escola de Engenharia de São Carlos) Universidade de São Paulo - USP, São Carlos, SP, 2007.

[5] CRUZ, Luiz O. M. Pavimento intertravado de concreto: estudo dos elementos e métodos de dimensionamento. Jun. 2003, 281 f. Tese de Mestrado (Programa de Pós-Graduação de Engenharia) - Universidade Federal do Rio de Janeiro - UFRJ, Rio de Janeiro, RS, 2003.

[6] Associação Brasileira de Normas Técnicas - ABNT. Norma Brasileira Regulamentadora - NBR. NBR 5736: 1991 - Cimento Portland pozolânico. 1. ed. 5 p. Rio de Janeiro: ABNT, 1991.

[7] . NBR 7211: 2009 - Agregado para concreto: Especificações. 3. ed. 9 p. Rio de Janeiro: ABNT, 2009.

[8] NBR 5733: 1991 - Cimento Portland de alta resistência inicial. 1. ed. 5 p. Rio de Janeiro: ABNT, 1991.

[9] de Janeiro: ABNT, 2009

[10] _. NBR NM 27: 2001 - Agregados: Redução da amostra de campo para ensaios de laboratório. 1. ed. 7 p. Rio de Janeiro: ABNT, 2001.

[11] _ _ NBR NM 248: 2001 - Agregados: Determinação da composição granulométrica. 1. ed. 6 p. Rio de Janeiro: ABNT, 2001.

[12] . NBR NM 45: 2006 - Agregados: Determinação da massa unitária e volume dos vazios. 1. ed. 8 p. Rio de Janeiro: ABNT, 2006.

[13] . NBR 9939: 2011 - Agregado graúdo: Determinação do teor de umidade total - Método de ensaio. 2. ed. 3 p. Rio de Janeiro: ABNT, 2011.

[14] . NBR 7809: 2006 - Agregado graúdo: Determinação do índice de forma pelo método do paquímetro - Método de ensaio. 1. ed. 3 p. Rio de Janeiro: ABNT, 2008.

[15] MACHADO, Rodrigo. Estudo aplicado da solução de projeto de pavimentação para pátio de estacionamento de ônibus. 2015. $110 \mathrm{f}$. Trabalho de Conclusão de Curso (Curso de Engenheiro de Infraestrutura - Centro de
Engenharias da Mobilidade - CEM) - Universidade Federal de Santa Catarina - UFSC, Joinville, SC, 2015.

[16] VARGAS, Alexandre S. de. Estudo da viabilidade do uso do pó de aciaria elétrica a arco na confecção de blocos de concreto para pavimentação. 2002. 166 f. Dissertação de Mestrado (Programa de Pós-Graduação em Engenharia de Minas, Metalúrgica e de Materiais - PPGEM) - Universidade Federal do Rio Grande do Sul - UFRGS, Porto Alegre, RS, 2002.

[17] SANTOS, Cassiano R. dos. Estudo da utilização de rejeitos de carvão mineral na fabricação de blocos de concreto para pavimentação em substituição ao agregado miúdo natural. Set. 2012. $161 \mathrm{f}$. Tese de Mestrado (Programa de Pós-Graduação em Engenharia de Minas, Metalúrgica e de Materiais PPGE3M) - Universidade Federal do Rio Grande do Sul - UFRGS, Porto Alegre, RS, 2012. 